\title{
Atopy, immunological changes, and respiratory function in bronchiectasis
}

\author{
MB MURPHY, DJ REEN, MX FITZGERALD \\ From the Medical Professorial Unit, St Vincent's Hospital; and the Children's Research Centre, Our Lady's \\ Hospital for Sick Children, Dublin
}

ABSTRACT Cystic fibrosis has been reported to be associated with an increased prevalence of atopy and reversible airways obstruction. To determine whether such features can also result from other chronic suppurative lung infections, we studied 23 patients with proved bronchiectasis, and 23 age and sex matched normal controls. A personal or family history of atopy was reported with equal frequency in the two groups. Although the groups displayed a similar prevalence of positive immediate hypersensitivity skinprick test responses, the positive patients reacted to more antigens $(p<0.05)$ and had larger weal diameters $(p<0.01)$ than the positive controls. Other indices, such as blood eosinophil counts and serum IgE, did not differ significantly. Serum concentrations of immunoglobulins $\mathrm{G}, \mathrm{A}$, and $\mathrm{M}$ and of the four IgG subclasses tended to be higher in patients than controls, but only in the case of $\operatorname{IgA}(p<0.01)$ was this difference significant. No case of IgG subclass deficiency was noted. The patients displayed significant airflow obstruction, the mean basal one second forced expiratory volume $\left(\mathrm{FEV}_{1}\right)$, forced vital capacity (FVC), and peak expiratory flow rate (PEFR) being 67\%, 77\%, and 67\% of their predicted values. There was evidence of a significant reversible obstructive component in that $\mathrm{FEV}_{1}$ or PEFR or both increased by $15 \%$ or more in nine of the 23 patients after inhalation of fenoterol, the mean increases in $\mathrm{FEV}_{1}, \mathrm{FVC}$, and PEFR for the whole group being $9.5 \%, 11 \%$, and $16.9 \%$. These results indicate that while bronchiectasis provokes a hyperimmune response it differs from cystic fibrosis in that there is no significant increase in the prevalence of atopy. The finding of reversible airways obstruction, however, suggests that bronchodilators may be useful adjuncts to treatment.

An increased prevalence of atopy and reversible airways obstruction has been reported in patients with cystic fibrosis ${ }^{1-4}$ but its significance is unclear. Some authors suggest that atopy is genetically an intrinsic part of the cystic fibrosis syndrome, while others propose that it is a consequence of prolonged, excessive stimulation of the immune system by chronic infection. To test the hypothesis that chronic infection per se predisposes to atopy, we studied patients with bronchiectasis, a condition where pulmonary pathological changes are in many respects similar to those of cystic fibrosis.

Previous studies of atopy in bronchiectasis have been few and have produced contradictory results. Varpela et $a l,{ }^{5}$ in an uncontrolled study, reported an increased prevalence of atopy; while Hilton and

Address for reprint requests: Professor MX FitzGerald, Medical Professorial Unit, St Vincent's Hospital, Dublin 8, Eire.

Accepted 14 October 1983
Doyle, ${ }^{6}$ using diseased controls, and Nogrady et al, ${ }^{7}$ in another uncontrolled study, failed to confirm this. We have therefore studied a comprehensive range of atopic indices and the extent of reversible airways obstruction in 23 patients with bronchiectasis and in age and sex matched controls. We have measured total serum IgG, IgA, and IgM, and we have also measured IgG subclasses, which have not previously been evaluated in bronchiectasis.

\section{Methods}

Twenty-three patients (17 female and six male) attending the chest clinic at St Vincent's Hospital volunteered for study. Their mean age was 36 years (range 14-60). Each had chronic productive cough and bronchographically proved bronchiectasis. Patients with cystic fibrosis or allergic bronchopulmonary aspergillosis were excluded. Twenty-three age and sex matched normal controls, either hospital 
personnel or volunteer blood donors, were similarly studied.

All subjects answered a respiratory questionnaire, documenting family history of chest disease, smoking habits, and current symptoms such as cough, sputum quality and volume, haemoptysis, and dyspnoea. Additionally, in the case of the patients with bronchiectasis, duration of symptoms, precipitating illness, concurrent or past illness, and current treatment were recorded. Each subject completed an atopy questionnaire, recording personal or family history of asthma, wheeze, eczema, urticaria, allergic rhinitis, angioneurotic oedema, contact dermatitis, and drug allergy. A subject was deemed to have a positive atopic history if one or more of these features were present. A positive family history was assumed if any first degree relative had one or more positive features.

Patients and controls underwent skin hypersensitivity testing by the prick method, using a diluent control, and 13 commercially available common allergen extracts: grass pollen, tree pollen, house dust, Dermatophagoides pteronyssinus, mixed feathers, cat fur, Aspergillus fumigatus, $A$ terreus, Cladosporium spp, Timothy grass, and three mixed mould extracts (Bencard M5, M10, and M11). A weal of $3 \mathrm{~mm}$ or more in diameter, on the volar surface of the forearm, constituted a positive result.

Peak expiratory flow rate (PEFR), measured with a Wright peak flow meter; forced expiratory volume in one second $\left(\mathrm{FEV}_{1}\right)$; and forced vital capacity (FVC), measured with a dry spirometer (Vitalograph), were recorded at rest. They were repeated 10 minutes after inhalation of $360 \mu \mathrm{g}$ of the $\beta_{2}$ adrenergic agonist fenoterol. Subjects were studied at the same time of day to eliminate diurnal variation, and the best of three attempts at each test was recorded. Patients using bronchodilators or steroids withheld their medications, according to the protocol of Chai et al. $^{8}$

Serum IgE was measured by radioimmunoassay and IgG, IgA, and IgM by radial immunodiffusion. IgG subclasses were measured by the radial immunodiffusion method of Mancini ${ }^{9}$ (antisera provided courtesy of Seward Laboratories and the Netherlands Blood Transfusion Service, with World Health Organisation reference controls). Aspergillus fumigatus precipitins were sought in all cases by the agar gel diffusion technique of Longbottom and Pepys. ${ }^{10}$ Blood eosinophil counts were made by the counting chamber method.

\section{Results}

CHARACTERISTICS OF GROUPS

The mean duration of respiratory symptoms in the
23 patients was 21 years (range 2-50), beginning before the age of 10 in $14(61 \%)$. The main symptoms were chronic productive cough, which was present in all 23 patients; dyspnoea on exertion, present in $17(74 \%)$; and haemoptysis, which was reported in $14(61 \%)$. Lung auscultation identified crepitations in 14 patients $(61 \%)$ and $11(48 \%)$ had finger clubbing.

In the patients the mean daily sputum volume at the time of the study was $60 \mathrm{ml}$ and, although all had purulent sputum, organisms were cultured in only 10 cases $(43 \%)$. Haemophilus infuenzae was the commonest pathogen, being found in eight of the 10 culture positive patients, while pneumococci were found in two and Pseudomonas aeruginosa in one. The extent of the disease on bronchography varied from a single lobe affected in four patients to all five lobes in two, the mean being $2 \cdot 8$ diseased lobes per patient. Eleven patients were taking prophylactic antibiotics and five, known to have reversible airways obstruction, took inhaled or oral bronchodilators. Three of the five were having inhaled corticosteroid treatment and two with severe wheeze were taking prednisolone $5 \mathrm{mg}$ daily.

\section{ATOPIC INDICES}

There was no significant difference between patients and controls in the prevalence of atopic symptoms (12 and 10 respectively) or in the prevalence of family atopy (12 and 11). Individual atopic symptoms, with the exception of wheeze (five patients but no control), occurred with the same frequency in both groups (table 1).

Responses to skinprick tests were positive in seven patients and six controls but patients with positive results had significantly more reactions (mean 5.4) than controls with positive results (mean $2 \cdot 6 ; p<0.05)$. Patients with positive responses also had a larger mean weal diameter $(5.3 \mathrm{~mm})$ than controls with positive responses $(3.9 \mathrm{~mm})(\mathrm{p}<0.01)$. Table 2 illustrates the prevalence of positive reactions in each group. Three patients, but no control, reacted to non-specific composite mould extracts; two of these also reacted to $A$ fumigatus. These

Table 1 Atopic symptoms in 23 patients with bronchiectasis and 23 normal controls

\begin{tabular}{llll}
\hline & \multicolumn{3}{l}{ No (\%) of } \\
\cline { 2 - 3 } Symptoms & patients & controls & $p^{*}$ \\
\hline Wheeze & $5(22)$ & & $<0 \cdot 05$ \\
Eczema & $3(13)$ & $2(9)$ & NS \\
Contact dermatitis & $6(26)$ & $4(17)$ & NS \\
Allergic rhinitis & $2(9)$ & $2(9)$ & NS \\
Urticaria & $4(17)$ & $4(17)$ & NS \\
Drug sensitivity & $3(13)$ & & NS \\
\hline
\end{tabular}

*Fisher's exact probability test. NS-not significant. 
Table 2 Results of immediate hypersensitivity skin tests in patients and controls

\begin{tabular}{|c|c|c|c|c|c|}
\hline \multirow[b]{2}{*}{ Allergen } & & \multicolumn{2}{|c|}{ Patients } & \multicolumn{2}{|c|}{ Controls } \\
\hline & & $\begin{array}{l}\text { Number } \\
\text { positive }\end{array}$ & $\begin{array}{c}\text { Mean } \\
\text { diameter }(\mathrm{mm})\end{array}$ & $\begin{array}{l}\text { Number } \\
\text { positive }\end{array}$ & $\begin{array}{c}\text { Mean } \\
\text { diameter }(\mathrm{mm})\end{array}$ \\
\hline $\begin{array}{l}\text { Aspergillus fumigatus } \\
\text { Aspergillus terreus } \\
\text { House dust } \\
\text { Dermatophagoides pteronyssinus } \\
\text { Mixed moulds (M5) } \\
\text { Mixed moulds (M10) } \\
\text { Mixed moulds (M11) } \\
\text { Pollen (trees) } \\
\text { Pollen (grass) } \\
\text { Cat fur } \\
\text { Mixed feathers } \\
\text { Cladosporium spp } \\
\text { Timothy grass } \\
\text { Control (diluent) }\end{array}$ & & $\begin{array}{l}2 \\
3 \\
6 \\
5 \\
2 \\
3 \\
1 \\
3 \\
1 \\
5 \\
4 \\
1 \\
2 \\
0\end{array}$ & $\begin{array}{r}9 \\
5 \\
4 \\
6 \\
4 \\
4 \\
4 \\
4 \\
7 \\
5 \\
4 \\
6 \\
10 \\
-\end{array}$ & $\begin{array}{l}0 \\
2 \\
5 \\
2 \\
0 \\
0 \\
0 \\
0 \\
1 \\
1 \\
4 \\
0 \\
1 \\
0\end{array}$ & $\begin{array}{l}\overline{5} \\
4 \\
3 \\
\overline{-} \\
\overline{-} \\
\overline{4} \\
4 \\
\frac{4}{5}\end{array}$ \\
\hline $\begin{array}{l}\text { No of positive reactions } \\
\text { (per "positive" subject) }\end{array}$ & $\begin{array}{l}\text { Patients } \\
(\mathrm{n}=7) \\
5 \cdot 4\end{array}$ & $\begin{array}{l}\mathrm{p}< \\
\text { (unp }\end{array}$ & $\begin{array}{l}\text { Controls } \\
(n=6) \\
2 \cdot 6 \\
t)\end{array}$ & & \\
\hline $\begin{array}{l}\text { Mean weal diameter } \\
\text { (per "positive" subject) }\end{array}$ & $5.3 \mathrm{~mm}$ & $\begin{array}{l}\mathrm{p}< \\
\text { (unp }\end{array}$ & t) $3.9 \mathrm{~mm}$ & & \\
\hline
\end{tabular}

three mould positive patients, however, displayed no enhancement of other allergic phenomena. For example, only one had a raised IgE concentration and all had normal $\mathrm{IgG}_{4}$ concentrations. Similarly, positive reactions to moulds were not related to disease severity or duration, as patients with equally severe disease, of longer duration, had no positive reactions. The sole patient with a documented pseudomonas infection (but a negative result in the sweat test) had negative skin test responses. No subject had aspergillus precipitins.

There were no significant differences between the groups in blood eosinophil counts (patients' mean (SD) count was $226(212) / \mathrm{mm}^{3}$ and the control count was $\left.167(117) / \mathrm{mm}^{3}\right)$ or in serum IgE concentrations (patients: $44(61) \mathrm{U} / \mathrm{ml}$; controls: 57 (61) $\mathrm{U} / \mathrm{ml}$ ). None of the atopic indices correlated significantly with disease severity or duration, pulmonary function, the presence or absence of $H$ infuenzae infection, or prophylactic antibiotic

\section{treatment.}

\section{IMMUNOGLOBULIN STUDIES}

The serum concentrations of immunoglobins tended to be higher in the patients (table 3 ). The serum IgA concentration was significantly higher in the patients than in the controls $(p<0.01)$ and it was significantly correlated with sputum volume and the number of diseased lobes $(r=0.7, p<0.01$ for both). No subject had IgA deficiency. Although patients' total IgG $(13.08(4.96) \mathrm{g} / \mathrm{l})$ did not differ significantly from that of controls $(12.61(2 \cdot 86) \mathrm{g} / \mathrm{l})$, three patients but no control had raised concentrations. These three patients had the most severe disease, defined bronchographically and by volume of daily sputum. The serum concentrations of IgM and the four IgG subclasses were similar in the two groups. Serum concentrations of the IgG subclasses showed a wide range of values (fig 1 ). In none of the subclasses was serum concentration correlated with

Table 3 Serum immunoglobulins in 23 patients with bronchiectasis and 23 normal controls

\begin{tabular}{|c|c|c|c|}
\hline Immunoglobulins & Patients (mean $(S D)$ ) & Controls (mean $(S D)$ ) & $p^{*}$ \\
\hline $\begin{array}{l}G(g / l) \\
A(g / l) \\
M(g / l) \\
E(U / m l)\end{array}$ & $\begin{array}{r}13.08(4.96) \\
3.38(1.66) \\
1.75(1.01) \\
44(61)\end{array}$ & $\begin{array}{l}12 \cdot 61(2 \cdot 86) \\
2 \cdot 00(0 \cdot 48) \\
1 \cdot 70(0 \cdot 53) \\
57(61)\end{array}$ & $\begin{array}{l}\text { NS } \\
<0 \cdot 01 \\
\text { NS } \\
\text { NS }\end{array}$ \\
\hline $\begin{array}{l}\mathrm{IgG}_{1}(\mathrm{~g} / \mathrm{l}) \\
\mathrm{IgG}_{2}(\mathrm{~g} / \mathrm{l}) \\
\mathrm{IgG}_{3}(\mathrm{~g} / \mathrm{l}) \\
\mathrm{IgG}_{4}(\mathrm{~g} / \mathrm{l})\end{array}$ & $\begin{array}{l}\text { Median (range) } \\
6 \cdot 6(4 \cdot 3-19 \cdot 5) \\
3 \cdot 4(2 \cdot 0-8 \cdot 7) \\
0 \cdot 99(0 \cdot 31-2 \cdot 46) \\
0 \cdot 36(0 \cdot 1-3 \cdot 75)\end{array}$ & $\begin{array}{l}\text { Median (range) } \\
7.5(5.0-12 \cdot 1) \\
3.2(1.9-5.7) \\
0.74(0.24-1.5) \\
0.44(0.15-1.32)\end{array}$ & $\begin{array}{l}\text { NS } \\
\text { NS } \\
\text { NS } \\
\text { NS }\end{array}$ \\
\hline
\end{tabular}

*Mann Whitney test; $p=$ level of significance. NS $=p>0.05$. 


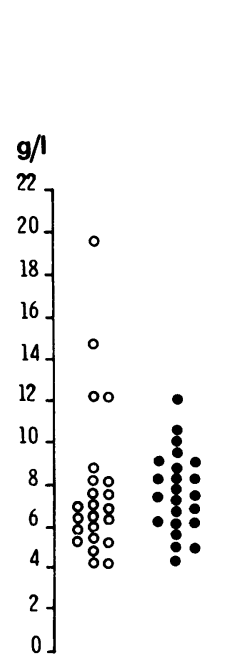

$\mathbf{G 1}_{1}$

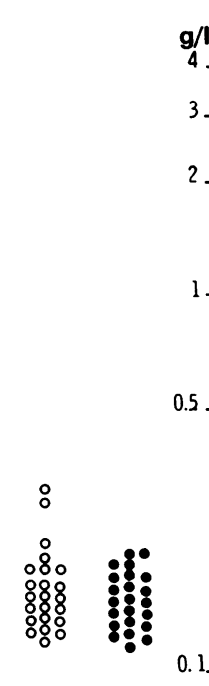

G2

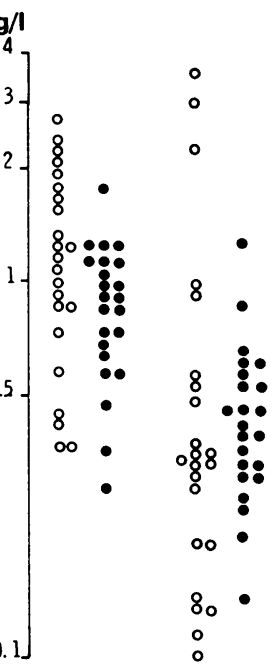

G3
G4

Fig 1 IgG subclass concentrations in 23 patients with bronchiectasis (O) and 23 normal controls (O). IgG, and $\mathrm{IgG}_{2}$ are on a linear scale and $\mathrm{IgG}_{3}$ and $\mathrm{IgG}_{4}$ on $\mathrm{a}$ logarithmic scale.

disease severity as defined by daily sputum volume, by number of diseased lobes on bronchography or by disease duration. Total serum IgG calculated by the summation of the values for the individual subclasses showed good agreement with the estimated value.

To exclude the possibility that the prevalence of atopic indices and immunoglobin concentrations in the group of patients were modified by the use of steroids in a subgroup, the data on the 18 untreated patients and their matched controls were reanalysed separately. Again, there was no significant differ-
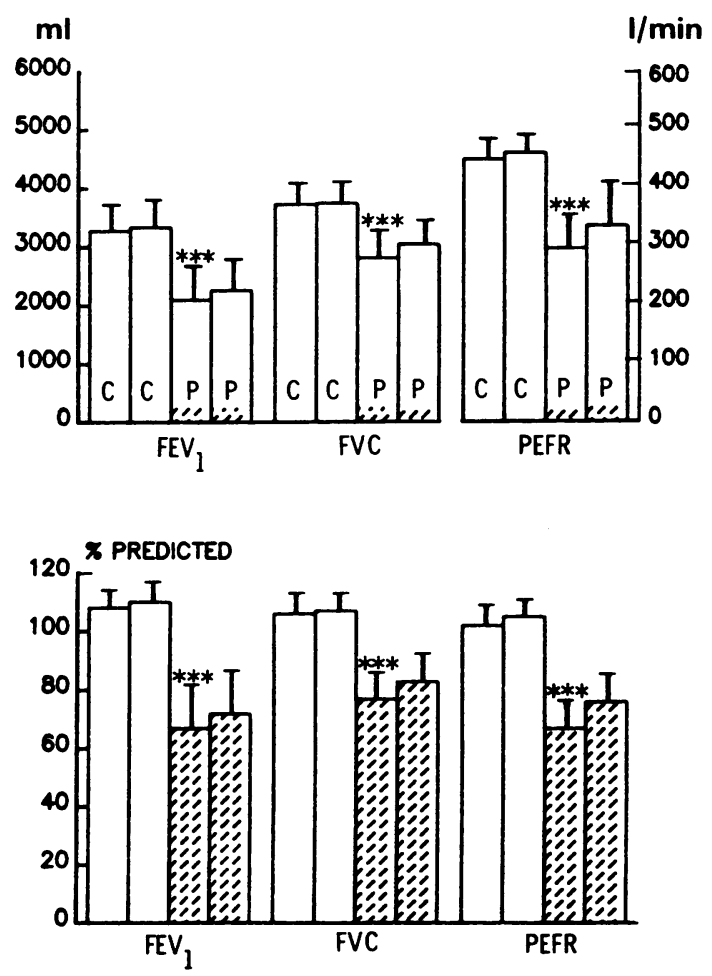

Fig 2 Pulmonary function in bronchiectasis. The upper panel illustrates the forced expiratory volume in one second $(F E V$, ), forced vital capacity (FVC), and peak expiratory flow rate $(P E F R)$ in 23 patients $(P)$ and 23 controls $(C)$ before (left hand column in each pair) and after (right hand column) inhalation of fenoterol. The lower panel shows these pulmonary function indices expressed as percentages of the predicted values. Results are expressed as means and standard errors. ${ }^{* * *} p<0.001$ for the comparison of patients and controls before administration of bronchodilator.

Table 4 Inftuence of fenoterol $(360 \mu \mathrm{g})$ on pulmonary function in 23 patients with bronchiectasis and 23 normal controls (values are means with standard deviations in parentheses)

\begin{tabular}{|c|c|c|c|c|c|}
\hline & \multicolumn{2}{|l|}{ Patients } & \multicolumn{2}{|l|}{ Controls } & \multirow[b]{2}{*}{$p^{*}$} \\
\hline & Before & After & Before & After & \\
\hline $\begin{array}{l}\mathrm{FEV}_{1} \% \text { predicted } \\
\text { Mean } \% \text { change }\end{array}$ & $\begin{array}{c}2110(1070) \\
67(29)\end{array}$ & $\begin{array}{c}2260(1040) \\
9 \cdot 5(12 \cdot 2)\end{array}$ & $\begin{array}{c}3270(640) \\
108(15)\end{array}$ & $\begin{array}{l}3330(640) \\
2 \cdot 1(3 \cdot 7)\end{array}$ & $\begin{array}{l}<0.001 \\
<0.01\end{array}$ \\
\hline $\begin{array}{l}\text { FVC }(\mathrm{ml}) \\
\% \text { predicted } \\
\text { Mean \% change }\end{array}$ & $\begin{array}{c}2810(1210) \\
77(23)\end{array}$ & $\begin{array}{l}3040(1110) \\
11 \cdot 0(15 \cdot 1)\end{array}$ & $\begin{array}{c}3720(740) \\
106(15)\end{array}$ & $\begin{array}{l}3740(690) \\
0.9(3 \cdot 5)\end{array}$ & $\begin{array}{l}<0.001 \\
<0.001\end{array}$ \\
\hline $\begin{array}{c}\text { PEFR }(1 / \text { min }) \\
\% \text { predicted } \\
\text { Mean } \% \text { change }\end{array}$ & $\begin{array}{c}297(129) \\
67(31)\end{array}$ & $\begin{array}{r}335(125) \\
16 \cdot 9(20 \cdot 1)\end{array}$ & $\begin{array}{l}449(90) \\
102(14)\end{array}$ & $\begin{array}{l}460(93) \\
2 \cdot 9(6 \cdot 9)\end{array}$ & $\begin{array}{l}<0.001 \\
<0.005\end{array}$ \\
\hline
\end{tabular}

*Unpaired $t$ test.

FVC-forced vital capacity; PEFR—-peak expiratory flow rate. 
ence between the groups in any of the atopic indices and the excess of $\operatorname{IgA}$ in patients was confirmed.

\section{PULMONARY FUNCTION}

As a group the patients displayed appreciable airways obstruction (table 4). The mean $\mathrm{FEV}_{1}$ of the patients was below normal and significantly lower than that of controls. Furthermore, the mean increase in $\mathrm{FEV}_{1}$ after inhalation of fenoterol was significantly greater in patients than in controls. Similarly, the mean PEFR of the patients was lower in patients than in controls and showed a significantly greater improvement after inhalation of fenoterol. Finally, the FVC showed significantly greater improvement in the patients than in the controls. Only five of the nine patients with significant reversibility of airways obstruction (that is, improvement of $15 \%$ or greater in $\mathrm{FEV}_{1}$ or PEFR) admitted to having asthma or wheeze on the questionnaire.

\section{Discussion}

Several studies in patients with cystic fibrosis have showed an increased prevalence of atopy. ${ }^{1-3} \mathrm{~A}$ recent report from our own group ${ }^{4}$ records a greater prevalence of personal and family history of atopy, more positive skin test responses, and higher IgE and $\mathrm{IgG}_{4}$ concentrations in older patients with cystic fibrosis than in matched controls. The present study of a group of patients not with cystic fibrosis but with moderately severe bronchiectasis, of long duration, suggests that chronic bronchial suppuration per se does not induce clinically significant atopy. It furthermore shows the existence of considerable airways obstruction in bronchiectasis and a major reversible component in a substantial subgroup.

The reported prevalence of atopy in patients with bronchiectasis varies from $30 \%^{6}$ to $42 \% .^{5}$ The application of wider diagnostic criteria probably explains the higher prevalence of personal atopy $(52 \%)$ and family atopy $(53 \%)$ in our patients and the apparently high prevalence of both phenomena in our normal controls. Wide variation in diagnostic criteria has led to confusion in published reports about atopy in normal and diseased populations, ${ }^{11}$ and underlines the absolute necessity for inclusion of normal controls in all studies purporting to show and interpret differences between groups. Previous studies of bronchiectasis using no controls ${ }^{57}$ or diseased controls ${ }^{6}$ have resulted in inconclusive evidence of enhanced atopy in this condition.

The serum IgE concentrations and blood eosinophil counts of our patients with bronchiectasis did not differ from those of the normal controls-in contrast to the findings of a study of patients with cystic fibrosis, where both of these indices were elevated. ${ }^{4}$ Similarly, our bronchiectasis group displayed no excess of positive reactions to immediate hypersensitivity skin tests, unlike the patients with cystic fibrosis previously reported. ${ }^{4}$ The fact that those patients with bronchiectasis with a positive skin test response reacted to more antigens, particularly fungi, and had larger weals than controls suggests that chronic bronchial suppuration may enhance or exaggerate a pre-existing atopic tendency, rather than promote atopy de novo.

Serum concentrations of $\mathrm{IgG}_{4}$ were similar in patients with bronchiectasis and controls. This immunoglobulin subclass has recently been implicated in the pathogenesis of atopic syndromes, ${ }^{12-14}$ including asthma, ${ }^{1516}$ and we have shown that adolescent patients with cystic fibrosis have raised concentrations. ${ }^{4}$ The finding of normal $\mathrm{IgG}_{4}$ concentrations in patients with bronchiectasis adds further support to the suggestion that this condition does not induce an atopic state.

The serum immunoglobulin concentrations tended to be higher in the patients than in controls, supporting the view that bronchiectasis provokes a hyperimmune response. ${ }^{6}$ There is recent evidence that selective deficiencies of individual IgG subclasses can coexist with normal or even raised total IgG concentrations. ${ }^{17}$ Such selective immune deficiency may predispose to recurrent infection, ${ }^{18}$ and respond to treatment with hyperimmune globulin. We found no evidence, however, of a selective subclass deficit in our bronchiectasis group. Both patients and controls displayed wide ranges in serum concentrations of all subclasses, similar to those found in previous normal population studies. ${ }^{19-22}$

The discovery of considerable reversible airways obstruction in nine of the patients confirms the findings of previous studies. Nogrady' reported increases in PEFR $(25.8 \%)$ and FEV $_{1}(16.4 \%)$ after inhaled or intravenous salbutamol in a group of patients with comparable disease; and Varpela ${ }^{5}$ demonstrated bronchial hypersensitivity to inhaled histamine in bronchiectasis. This hyperreactivity may result from increased access to toxins through infected mucosa with consequent local histamine release, local autonomic reflex stimulation, or direct smooth muscle stimulation. ${ }^{23} 24$ Bronchoconstriction resulting from these local mechanisms, however, must not be interpreted as evidence of generalised atopy. It has been suggested that asthmatics are more prone to develop bronchiectasis than normal people but our study was not designed to examine this. Four of the patients with reversible airway obstruction had other atopic features-for example, eczema, urticaria, and allergic rhinitis-suggesting that they had extrinsic asthma, but the remaining 
five did not. Nevertheless, the fact that four of the nine patients with reversible airways obstruction denied having asthma or wheeze illustrates the need for a therapeutic trial of bronchodilators in all patients with bronchiectasis.

There are, of course, differences between patients with cystic fibrosis and with bronchiectasis. The mean ages of most reported series of patients with bronchiectasis are considerably higher than those for cystic fibrosis. Possibly pathological stimulation of an immature immune system in childhood, as in cystic fibrosis, may result in abnormal allergen responses in later life, such as are seen in older patients with cystic fibrosis. A more obvious difference between the two conditions is the nature of the respiratory flora. Haemophilus infuenzae and pneumococci predominate in bronchiectasis, ${ }^{625}$ while $P$ aeruginosa, Staphylococcus aureus, and fungi are more prevalent in cystic fibrosis. ${ }^{26}$ Indeed, it has been suggested, $P$ aeruginosa, especially the mucoid strain, rarely found in simple bronchiectasis, may be specifically responsible for the hypersensitivity to fungal antigens frequently seen in cystic fibrosis. ${ }^{27}$

In conclusion, this study has three implications. Firstly, it suggests that bronchiectasis, unlike cystic fibrosis, is not associated with clearcut atopy. Secondly, it shows that selective IgG subclass deficiency is unlikely to be an important factor in the pathogenesis of this condition. Finally, it shows the existence of appreciable reversible airways obstruction, which should be sought in all cases of bronchiectasis and treated appropriately.

We are grateful to the Medical Research Council of Ireland for their support, to Mr A O'Connor and Mrs G Lawless for technical assistance, and to Mrs N Martin for typing the manuscript.

\section{References}

' Warner O, Taylor BW, Norman AP, Soothill JF. Association of cystic fibrosis with allergy. Arch Dis Child 1976;51:507-11.

${ }^{2}$ Barren R, Cotton E, Larson G, Brooks J. The prevalence of atopy in cystic fibrosis. Proceedings of Cystic Fibrosis Club's eighteenth meeting London: Cystic Fibrosis Foundation, 1977:23.

${ }^{3}$ Counahan R, Mearns MB. Prevalence of atopy and exercise-induced bronchial lability in relatives of patients with cystic fibrosis. Arch Dis Child 1975;50:477-81.

${ }^{4}$ Tobin MJ, Maguire O, Reen D, Tempany E, FitzGerald MX. Atopy and bronchial reactivity in older patients with cystic fibrosis. Thorax 1980;36:807-13.

${ }^{5}$ Varpela E, Laitinen LA, Keskinen H, Korhola O. Asthma, allery and bronchial hyperreactivity to histamine in patients with bronchiectasis. Clin Allergy 1978;8:273-80.

${ }^{6}$ Hilton AM, Doyle L. Immunological abnormalities in bronchiectasis with chronic bronchial suppuration. $\mathrm{Br}$ $J$ Dis Chest 1978;72:207-16.

${ }^{7}$ Nogrady SG, Evans W, Davies BH. Reversibility of airways obstruction in bronchiectasis. Thorax 1978;33:635-7.

${ }^{8}$ Chai H, Farr RS, Froelich LA. Standardisation of bronchial inhalation challenge procedures. J Allergy Clin Immunol 1975;56:323-7.

${ }^{9}$ Mancini G, Carbonada AO, Heremans JF. Immunological quantitation of antigens by single radial immunodiffusion. Immunochemistry 1963;2: 235.

${ }^{10}$ Longbottom J, Pepys J. Pulmonary aspergillosis: diagnostic and immunological significance of antigens and C-substance in Aspergillus fumigatus. J Pathol Bacteriol 1964;88:141-51.

" Carr RD, Berke M, Becker SW. Incidence of atopy in the general population. Arch Dermatol 1964;89:2732.

${ }^{12}$ Bruynzeel PLB, Berrens L. IgE and IgG antibodies in specific human allergies. Int Arch Allergy Appl Immunol 1979;58:344-50.

${ }^{13}$ Parish WE. Short-term anaphylactic IgG antibodies in human sera. Lancet 1970;ii:591-2.

${ }^{14}$ Gwynn CN, Morrison-Smith J, Leon Leon G, Stanworth DR. IgE and $\operatorname{IgG}_{4}$ subclass in atopic families. Clin Allergy 1979;9:119-23.

is Gwynn CN, Morrison-Smith J, Leon Leon G, Stanworth DR. Role of $\mathrm{IgG}_{4}$ subclass in childhood allergy. Lancet $1978 ; \mathrm{i}: 910-1$.

${ }^{16}$ Devey ME, Panzani R. The IgG subclasses of antibodies to castor bean allergen in patients with allergic asthma; detection of a high incidence of antibodies of the $\mathrm{IgG}_{4}$ subclass. Clin Allergy 1975;5:353-61.

${ }^{17}$ Oxelius VA. Quantitative and qualitative investigations of serum IgG subclasses in immunodeficiency diseases. Clin Exp Immunol 1979;36:112-6.

${ }^{18}$ Oxelius VA. Chronic infections in a family with hereditary deficiency of $\mathrm{IgG}_{2}$ and $\mathrm{IgG}_{4}$. Clin Exp Immunol 1974;17:19-27.

${ }^{19}$ Reen DJ, Murphy MB, O' Connor A, FitzGerald MX IgG subclass levels in healthy Irish adults. Irish $\mathrm{J}$ Med Sci 1981;150:265-9.

${ }^{20}$ Shakib F, Stanworth DR, Drew R, Catty D. A quantitative study of the distribution of IgG subclasses in a group of normal human sera. J Immunol Methods 1975;8:17-28.

21 Van der Giersen M, Rossouw E, Algra-van Veen T, Van Loghem E, Zegers BJM, Sander PC. Quantitation of IgG subclasses in sera of normal adults and healthy children between four and 12 years of age. Clin Exp Immunol 1975;21:501-9.

${ }^{22}$ Oxelius VA. IgG subclass levels in infancy and childhood. Acta Paediatr Scand 1979;68:23-7.

${ }^{23}$ Boushey HA, Holtzman MJ, Sheller JR, Nadel JA. Bronchial hyperreactivity. Am Rev Respir Dis 1980;121:389-413.

${ }^{24}$ Empey DW, Laitinen LA, Jacobs L, Gold WM, Nadel NA. Mechanisms of bronchial hyperactivity in normal subjects after upper respiratory tract infection. $\mathrm{Am}$ Rev Respir Dis 1976;113:131-9.

${ }^{25}$ Cherniack NS, Carton BW. Factors associated with respiratory insufficiency in bronchiectasis. $\mathrm{Am} \mathrm{J}$ Med 1966;41:562-71.

${ }^{26}$ Hodson ME. Immunological abnormalities in cystic fibrosis: chicken or egg? Thorax 1980;35:801-6.

${ }^{27}$ Clarke CW, Hampshire P, Hannant C. Positive immediate skin tests in cystic fibrosis: a positive role for pseudomonas infection. Br J Dis Chest 1981;75:1521. 